\title{
Development and validation of a novel questionnaire for self-determination of the range of motion of wrist and elbow
}

\author{
Marc Schnetzke ${ }^{1}$, Svenja Schüler ${ }^{2}$, Holger Keil ${ }^{1}$, Sara Aytac ${ }^{1}$, Stefan Studier-Fischer ${ }^{1}$, Paul-Alfred Grützner ${ }^{1}$ \\ and Thorsten Guehring ${ }^{1,3^{*}}$
}

\begin{abstract}
Background: The aim of this study was to develop and validate a novel self-administered questionnaire for assessing the patient's own range of motion (ROM) of the wrist and the elbow.

Methods: In a prospective clinical study from January 2015 to June 2015, 101 consecutive patients were evaluated with a novel, self-administered, diagram-based, wrist motion assessment score (W-MAS) and elbow motion assessment score (E-MAS). The questionnaire was statistically evaluated for test-retest reliability, patient-physician agreement, comparison with healthy population, and influence of covariates (age, gender, affected side and involvement in workers' compensation cases).
\end{abstract}

Results: Assessment of patient-physician agreement demonstrated almost perfect agreement $(k>0.80)$ with regard to six out of eight items. There was substantial agreement with regard to two items: elbow extension $(k=0.76)$ and pronation $(k=0.75)$. The assessment of the test-retest reliability revealed at least substantial agreement $(k=0.70)$. The questionnaire revealed a high discriminative power when comparing the healthy population with the study group ( $p=0.007$ or lower for every item). Age, gender, affected side and involvement in workers' compensation cases did not in general significantly influence the patient-physician agreement for the questionnaire.

Conclusion: The W-MAS and E-MAS are valid and reliable self-administered questionnaires that provide a high level of patient-physician agreement for the assessments of wrist and elbow ROM.

Level of evidence: Diagnostic study, Level II

Keywords: Self-assessment, Measurement tool, Validity, Reliability, Range of motion, Wrist, Elbow, Questionnaire

\section{Background}

Assessing the patient's outcome and satisfaction is important in modern orthopedic practice [1-3]. Using questionnaires to evaluate patients with wrist and elbow disorders is widespread and has been shown to be valid and reproducible [4-9]. Self-reported outcome measures allow outcomes to be assessed from the

\footnotetext{
*Correspondence: guehring@uni-heidelberg.de

'Department for Trauma and Orthopaedic Surgery, BG Trauma Center Ludwigshafen at Heidelberg University Hospital, Ludwigshafen am Rhein, Germany

${ }^{3}$ Department for Trauma and Orthopaedic Surgery, BG Trauma Center Ludwigshafen at the University of Heidelberg, Ludwig Guttmann Strasse 13, 67071 Ludwigshafen am Rhein, Germany

Full list of author information is available at the end of the article
}

patient's perspective and do not require time in clinic or medical staff for data collection.

Common self-administered questionnaires for the determination of hand- and upper limp specific results of the wrist (e.g. patient-rated wrist evaluation, PRWE [8]) and of the elbow (e.g. The American Shoulder and Elbow Surgeons-Elbow, ASES-E [1]) enable the patient to assess the functional impairment of the joint, but they do not formally assess the range of motion, and patients have to attend clinic for this to be measured [10]. Therefore important data regarding the ROM would be lost in patients who are unable or unwilling to come to the outpatient clinic at the regular follow-up or for clinical research.

To our knowledge no validated self-assessment questionnaire for the ROM of the wrist or the elbow exists, 
which compares the agreement of the patient's outcome with the examination by a physician.

Therefore, the aim of the current study was to develop a self-administered, diagram-based wrist motion assessment score (W-MAS) and elbow motion assessment score (E-MAS) to enable the patients to assess their own ROM of the wrist and the elbow. We further evaluated validity and reliability of this novel questionnaire with respect to the accuracy of self-determination of the wrist and elbow ROM.

\section{Methods}

In this prospective, single-center study the novel questionnaire was evaluated in patients with elbow or wrist disorders. Before development of this novel questionnaire a PubMed search was performed to identify the currently available self-administered questionnaires for the wrist and elbow joints.

PubMed was searched in May 2016 for elbow- and wrist-specific MeSH-terms ('elbow' or 'wrist' in combination with 'scoring system,' 'outcome assessment', 'elbow disorder,' 'wrist disorder,' 'questionnaire,' 'instrument' and 'clinical evaluation'), with no limit regarding the year of publication.

The PubMed search revealed 19 available selfadministered questionnaires for the wrist- and elbowjoint, which are listed in Table 1 . These questionnaires were analyzed regarding the assessment and validation method for the ROM. Most questionnaires combine self-assessment of subjective criteria and measurement of objective criteria (ROM) by a physician.

\section{Questionnaire development}

A literature search was performed to determine the standard ROM of the elbow, the proximal and distal radioulnar joint (PRUJ and DRUJ) and the wrist (Table 2). Based on these data, a diagram-based questionnaire was developed.

The extension and flexion of the elbow and the radial and ulnar deviation of the wrist were imaged with increments of $10^{\circ}$. Forearm supination and pronation as well as the extension and flexion of the wrist were imaged with an increment of $20^{\circ}$. These increments have been chosen to improve reproducibility without loss of information. For the assessment of the ROM, photographs were taken of a volunteer with an unimpaired wrist and elbow function. The joint position was measured and the volunteer was asked to hold the position briefly for the photograph. Additionally, the correct joint angle was then controlled with an electronic measurement device of Microsoft Word $^{\text {tw }}$ to ensure an accurate joint position on each image (Additional file 1: E-MAS, Additional file 2: W-MAS).

Finally, the E-MAS consists of 15 images for the extension (seven items, E-Ext) and flexion (eight items, E-Flex) of the elbow and ten images for supination (six items, Sup) and pronation (five items, Pro) of the forearm. The W-MAS consists of nine images addressing the extension (five items, W-Ext) and flexion (four items, W-Flex) of the wrist and six images addressing the radial- (three items, Rad) and ulnar deviation (four items, Uln).

Supination and pronation was performed with $90^{\circ}$ of elbow flexion and the upper arm adjacent to the torso. To standardize forearm supination and pronation without rotation of the shoulder a short instructive direction was set in front of the related images. The objectivity of application and data interpretation (content validity) is guaranteed by the questionnaire-format with a clear answer form (possible-not possible) [11, 12].

\section{Questionnaire administration}

Prior to a physical examination, the patient was asked to fill out the questionnaire. According to the directions on the questionnaire, patients were asked to check whether they are able to achieve the movements on each photograph for the wrist and the elbow on both sides. After completion of the questionnaire, the actual elbow and wrist ROM of both sides was measured by a single examiner $[\mathrm{MS}]$ using a standard 12-inch goniometer, regardless of whether the wrist and/or the elbow were the affected joint. The examiner was blinded to the selfreported ROM.

For assessment of the test-retest reliability the questionnaire was sent to the patients after an average of 65 (SD 21) days after the visit to clinic to prevent recall bias. Additionally, the patients were asked if there had been a change in the motion of any involved joint, and they were excluded from the assessment of test re-testreliability in the case of a positive answer.

\section{Study population}

Between January 2015 and July 2015, 101 consecutive patients suffering from disorders of the wrist and/or elbow were recruited at our outpatient clinic for participation in this study. These patients were identified from a consecutive list of patients scheduled for a follow-up visit as a prospective cohort. The inclusion criteria were age over 18 and disorder of the wrist and/or the elbow on one side. A subset of 58 patients (those, who denied having an altered ROM at the time of re-test) was reassessed for evaluating the test-retest reliability.

Another 30 healthy people were recruited as a control group to test if the questionnaire can distinguish between patients with and without disorders of the wrist or elbow. The inclusion criteria for the control group were age over 18 and unimpaired function of the upper extremity. Exclusion criteria for control group and the study group were cognitive diseases, psychiatric diseases, communication problems or dyslexia. 
Table 1 Patient-administered questionnaires for the wrist and the elbow

\begin{tabular}{|c|c|c|c|c|}
\hline Questionnaire & Joint & $\begin{array}{l}\text { Self-assessment } \\
\text { of ROM }\end{array}$ & $\begin{array}{l}\text { Patient-physician } \\
\text { validated ROM }\end{array}$ & Literature \\
\hline $\begin{array}{l}\text { Disabilities of the Arm, } \\
\text { Shoulder and Hand (DASH) }\end{array}$ & Upper limb & No & & Beaton et al. [5] \\
\hline Patient-Rated Elbow Evaluation (PREE) & Elbow & No & & MacDermid et al. [22] \\
\hline $\begin{array}{l}\text { American Shoulder and Elbow } \\
\text { Surgeons-Elbow Score (ASES-E) }\end{array}$ & Elbow & No & & King et al. [1] \\
\hline Broberg and Morrey rating system (BMS) & Elbow & No & & Broberg et al. [23] \\
\hline Elbow Self-Assessment Score (ESAS) & Elbow & Yes & No & Beirer et al. [6] \\
\hline Oxford Elbow Score (OES) & Elbow & No & & Dawson et al. [24] \\
\hline Liverpool Elbow Score (LES) & Elbow & No & & Sathyamoorthy et al. [16] \\
\hline $\begin{array}{l}\text { Patient-Rated Tennis Elbow Evaluation } \\
\text { Questionnaire (PRTEE) }\end{array}$ & Elbow & No & & Vincent et al. [25] \\
\hline Ewald scoring system & Elbow & No & & Ewald [26] \\
\hline Khalfayan score & Elbow & No & & Khalfayan et al. [27] \\
\hline Patient-Rated Wrist Evaluation (PRWE) & Wrist & No & & MacDermid et al. [28] \\
\hline Michigan Hand Outcomes Questionnaire (MHOQ) & Wrist & No & & Chung et al. [29] \\
\hline Musculoskeletal Functional Assessment (MFA) & Upper limb & No & & Engelberg et al. [30] \\
\hline Modern Activity Subjective Survey of 2007 (MASS07) & Wrist & No & & Alexander et al. [4] \\
\hline Levine Questionnaire (LQ) & Wrist & No & & Levine et al. [31] \\
\hline Mayo Wrist Score & Wrist & Yes & No & Cooney et al. [32] \\
\hline Cooney and Bussey Score & Wrist & Yes & No & Cooney et al. [33] \\
\hline Adelaide Questionnaire & Wrist & No & & Bialocerkowski [34] \\
\hline Munich Wrist Questionnaire & Wrist & Yes & No & Beirer et al. [35] \\
\hline
\end{tabular}

\section{Statistical analysis}

Descriptive statistics (mean, standard deviation, median, interquartile range, absolute and relative frequencies) were calculated to characterize the study population. The W-MAS and E-MAS were validated according to the proposed quality criteria for measurement properties of health status questionnaires of Terwee et al. [12]. The statistical evaluation included the assessment of (1) test-retest reliability, (2) agreement analysis (criterion validity and construct validity with Spearman correlation of at least 0.7 ), (3) comparison with healthy population (responsiveness) and (4) influence of covariates (age, gender, affected side and involvement in workers' compensation cases). Floor and ceiling effects and interpretability were considered to be not relevant for

Table 2 Mean ROM of the elbow and the wrist regarding literature

\begin{tabular}{llll}
\hline Joint & Movement & Range & Literature \\
\hline Elbow & Extension-Flexion & $0-0-140$ & Lockard et al. [36] \\
PRUJ/DRUJ & Supination-Pronation & $90-0-70$ & Lockard et al. [36] \\
Wrist & Extension-Flexion & $70-0-80$ & Ryu et al. [37] \\
Wrist & Radial and Ulnar deviation & $30-0-20$ & Ryu et al. [37] \\
\hline
\end{tabular}

the validation of these questionnaires as no mean score can be achieved.

The self-assessments by patients and the assessments by physicians are both represented by ordinal variables (ROM categorized into 4 to 8 groups). In the case of a missing item, only this specific motion pattern could not be evaluated.

\section{Test-retest reliability}

The test-retest reliability defines the degree of agreement of repeated measurements in the same subjects measured to assess the repeatability and reproducibility of an instrument. The time period between the measurements should be long enough to avoid learning and memory effects, but at the same time short enough to ensure consistency of the clinical symptoms [12]. Our target was to perform retests 2 months after baseline assessment. According to literature the time interval should be at least 2 weeks to prevent recall bias [12].

Reliability between the repeated measurements was assessed using Spearman's rank correlation and Kendall's Tau b correlation coefficient. To assess the agreement, Cohen's kappa and the probability of exact agreement 
(number of test-retest agreements/n, expressed as percentage) were derived.

\section{Agreement analysis}

An agreement analysis assesses the extent to which a new instrument relates to the true value or to a gold standard value. In the context of assessing the ROM, industrial robotic devices and optical motion analysis can be considered as the gold standard [13, 14]. For practical reasons physician ratings were chosen as the reference in the current study. The Spearman rank correlation was used to evaluate the relation between patients' and physicians' response. A positive rating for the agreement analysis was assumed when the Spearman correlation was at least 0.7 [12]. To assess the agreement, the probability of exact and approximate agreement (expressed as percentage) and Cohen's kappa were calculated.

To investigate the agreement dependent on the severity of the disorder, we calculated rates of exact agreement and approximate agreement in three different categories (no/mild, moderate and severe disorder, Table 3). The classification of the severity of the disorders was adopted from the previous elbow and wrist specific sores $[15,16]$.

Exact agreement was defined as those cases in which physician and patient chose an identical response. Approximate agreement was defined as agreement within one grade, in a positive or negative direction.

\section{Comparison with healthy population}

To assess the extent to which the questionnaires could distinguish healthy persons from persons with wrist or elbow disorder, Mann-Whitney U-tests were performed to compare the scoring.

\section{Influence of covariates}

The influence of age (in decades), gender, affected side (dominant or non-dominant upper limb) and involvement

Table 3 Classification of three subgroups of severity of disorder for every item of the E-MAS and the W-MAS

\begin{tabular}{llll}
\hline & No/mild & Moderate & Severe \\
\hline $\begin{array}{llll}\text { Elbow (in degrees) } \\
\text { extension }\end{array}$ & $0-10$ & $20-30$ & $40-60$ \\
flexion & $130-140$ & $110-120$ & $70-100$ \\
supination & 90 & $50-70$ & $0-30$ \\
pronation & 70 & 50 & $0-30$ \\
Wrist (in degrees) & & & \\
extension & 70 & 60 & $0-40$ \\
flexion & 70 & 60 & $0-40$ \\
radial deviation & 20 & 10 & 0 \\
ulnar deviation & 30 & 20 & $0-10$ \\
\hline
\end{tabular}

in workers' compensation cases on the patientphysician agreement was analyzed using univariable logistic regression.

For agreement measures of categorical data, the benchmarks as described by Landis and Koch where used: 0.00 to $0.20,0.21$ to $0.40,0.41$ to $0.60,0.61$ to 0.80 , and 0.81 to 1.00 indicate poor, fair, moderate, substantial, and almost perfect agreement, respectively [17]. The agreement should be at least 0.70 to be adequate [12].

Benchmarks for the Spearman rank correlation are not consistent in the literature. We used 0.00 to $0.20,0.21$ to $0.50,0.51$ to 0.80 , and 0.81 to 1.0 indicating no, weak, moderate, and strong relationship, respectively.

A $p$-value $<0.05$ is considered as statistically significant in a descriptive manner. Statistical analysis was performed using SPSS (version 21.0 for Windows).

\section{Results \\ Study population}

Mean age of the study group was 54.9 years (range 20 to 84, SD 13.6), 57 (56.4\%) were male and 44 (43.6 \%) were female. In 55 patients (54.5\%) the right side and in 46 patients $(45.5 \%)$ the left side was affected. The dominant side was affected in 58 patients $(57.4 \%)$. Table 4 summarizes patient's diagnosis, representing a wide spectrum of traumatic and degenerative elbow and/or wrist disorders. Forty-one patients $(42.6 \%)$ were involved in workers' compensation cases. Assessment of the ROM of all patients by the physician revealed no significant difference in restriction of ROM between the proportion of elderly ( $\geq 54.2$ years, median) and younger patients (Additional file 3).

Table 4 Distribution of injury pattern

\begin{tabular}{ll}
\hline Diagnosis & No. patients (\%) \\
\hline Complex elbow dislocation & $27(26.7)$ \\
Radial head fracture & $19(18.8)$ \\
Distal radius fracture & $18(17.8)$ \\
Simple elbow dislocation & $8(7.9)$ \\
Distal humerus fracture & $6(5.9)$ \\
Monteggia like lesion & $5(5.0)$ \\
Humeral shaft fracture & $5(5.0)$ \\
Proximal ulnar fracture & $4(4.0)$ \\
Essex-Lopresti-Injury & $3(3.0)$ \\
Forearm shaft fracture & $2(2.0)$ \\
Arthritis of the elbow & $2(2.0)$ \\
Osteochondritis dissecans Capitellum humeri & $1(1.0)$ \\
Loose bodies elbow & $1(1.0)$ \\
Total & $101(100)$ \\
\hline
\end{tabular}


A subgroup of 58 patients (57.4\%) from the study population was evaluated for test-retest reliability. Mean age of this subgroup was 56.7 years (range 37 to 81, SD 11.7), 31 (53.4\%) were male and 27 (46.6\%) were female. Another 30 healthy participants were recruited as a control group, mean age was 24.9 years (range 20 to 61, SD 11.4), ten (33.3\%) were male and 20 (66.6 \%) were female. None of the 131 patients found any of the given instructions difficult to understand or to follow. The questionnaire took a maximum of $5 \mathrm{~min}$ for patients to complete.

\section{Test-retest reliability}

The retest was performed in 58 patients at 65 days (range 21 to 112, SD 21) following baseline assessment. Results of test-retest reliability are shown in Table 5 . The assessment of the test-retest reliability revealed at least substantial agreement $(\mathrm{k}=0.693)$. Three items showed almost perfect agreement. Spearman correlation demonstrated moderate correlation for radial deviation of the wrist and strong correlation for the other seven items (0.849-0.998).

\section{Agreement analysis}

Results on patient-physician agreement are shown in Table 6. Assessment of patient-physician correlation demonstrated almost perfect agreement $(\mathrm{k}>0.80)$ with regard to six of the eight items. There was substantial agreement with regard to two items: elbow extension $(k=0.764)$ and pronation $(k=0.749)$. Spearman correlation was at least 0.882 indicating a strong correlation for all items. Exact agreement between the patient and the rating of the physician was found in 82.1 to $95 \%$ dependent on the tested movement and they were in approximate agreement (within one value) in at least $98 \%$ of cases.

In the case of disagreement between the physician and patient responses, patients tended to err toward underestimating their ROM, meaning that the patient rated the ROM worse than the physician did. In 2-12.9 \% patients tended to err towards underestimating their ROM and in 1 to $5 \%$ patients tended to err towards overestimating their ROM.

The analysis of exact agreement dependent on the severity of the disorder demonstrated that patients tended to miss exact agreement with increasing severity of the disorder in five of eight items (Figs. 1 and 2). Patients with a severe restriction of the elbow extension $(n=8)$ showed an exact agreement in only $50 \%$ of cases. In the other items exact agreement was found in at least $69.2 \%$ in patients with a severe restriction of joint movement.

\section{Comparison with healthy population}

The comparison of the study population with the healthy control group demonstrated that the E-MAS and the W-MAS are able to distinguish between healthy people and patients with restriction of wrist or elbow joint motion (Table 7).

\section{Influence of basic demographic data}

Logistic regression analysis showed a significant effect of age on the ability to accurately assess elbow extension $(p=0.034)$. Younger patients were reliably able to identify elbow extension using the questionnaire, whereas elderly patients made significantly more errors. In all other items age did not affect the ability to achieve exact agreement with the questionnaire $(p>0.05)$ and the OR was between 0.639 and 1.254 .

No statistically significant association between ability to accurately assess wrist or elbow ROM and gender $(p>0.05)$ or involvement of the dominant side $(p>0.05)$ was observed.

Involvement with workers' compensation cases significantly affected the ability to accurately assess the pronation $(p=0.039)$. All other items were not significantly influenced by the involvement with workers' compensation $(p>0.05)$.

Table 5 Statistics for test-retest reliability for the different parts of the questionnaire, $n=58$

\begin{tabular}{|c|c|c|c|c|}
\hline$n=58$ & Kendall-Tau-b (95 \%-Cl) & $\begin{array}{l}\text { Spearman's rank correlation coefficient } \\
(95 \% \text {-CI) }\end{array}$ & $\begin{array}{l}\text { Cohen's kappa } \\
(95 \%-C l)\end{array}$ & Exact agreement (in \%) \\
\hline \multicolumn{5}{|l|}{ Elbow } \\
\hline extension & $0.87(0.73-0.96)$ & $0.90(0.78-0.98)$ & $0.78(0.64-0.90)$ & 82.8 \\
\hline flexion & $0.91(0.82-0.99)$ & $0.94(0.85-1.00)$ & $0.81(0.69-0.93)$ & 86.2 \\
\hline supination & $0.86(0.76-0.94)$ & $0.89(0.78-0.96)$ & $0.73(0.56-0.87)$ & 84.4 \\
\hline pronation & $0.87(0.73-0.96)$ & $0.88(0.76-0.97)$ & $0.77(0.60-0.91)$ & 87.9 \\
\hline \multicolumn{5}{|l|}{ Wrist } \\
\hline extension & $0.98(0.96-1.00)$ & $1.00(0.99-1.00)$ & $0.88(0.75-1.00)$ & 94.8 \\
\hline flexion & $0.99(0.97-1.00)$ & $1.00(0.99-1.00)$ & $0.91(0.79-1.00)$ & 96.5 \\
\hline radial deviation & $0.76(0.52-0.95)$ & $0.76(0.52-0.95)$ & $0.76(0.51-0.95)$ & 91.4 \\
\hline ulnar deviation & $0.82(0.67-0.93)$ & $0.85(0.70-0.96)$ & $0.69(0.50-0.86)$ & 84.5 \\
\hline
\end{tabular}


Table 6 Statistics for patient-physician agreement for the different parts of the questionnaire, $n=101$

\begin{tabular}{|c|c|c|c|c|}
\hline$n=101$ & Kendall-Tau-b (95 \%-Cl) & $\begin{array}{l}\text { Spearman's rank correlation coefficient } \\
(95 \%-\mathrm{Cl})\end{array}$ & $\begin{array}{l}\text { Cohen's kappa } \\
(95 \%-C l)\end{array}$ & Exact agreement (in \%) \\
\hline \multicolumn{5}{|l|}{ Elbow } \\
\hline extension & $0.91(0.85-0.96)$ & $0.95(0.91-0.98)$ & $0.76(0.67-0.86)$ & 82.1 \\
\hline flexion & $0.95(0.90-0.99)$ & $0.97(0.93-1.00)$ & $0.86(0.78-0.93)$ & 90.1 \\
\hline supination & $0.93(0.85-0.99)$ & $0.94(0.87-1.00)$ & $0.89(0.81-0.96)$ & 93.0 \\
\hline pronation & $0.86(0.76-0.94)$ & $0.88(0.78-0.96)$ & $0.75(0.62-0.86)$ & 87.1 \\
\hline \multicolumn{5}{|l|}{ Wrist } \\
\hline extension & $0.95(0.91-0.98)$ & $0.97(0.94-1.00)$ & $0.83(0.73-0.92)$ & 90.1 \\
\hline flexion & $0.92(0.84-0.99)$ & $0.93(0.85-0.99)$ & $0.91(0.81-0.98)$ & 95.0 \\
\hline radial deviation & $0.89(0.80-0.98)$ & $0.90(0.80-0.98)$ & $0.87(0.76-0.97)$ & 95.0 \\
\hline ulnar deviation & $0.87(0.78-0.95)$ & $0.89(0.80-0.97)$ & $0.80(0.69-0.90)$ & 89.1 \\
\hline
\end{tabular}

Detailed analyses demonstrated that patients who were involved in workers' compensation cases $(n=42,41.6 \%)$ tended to err towards underestimating their ROM in 27 of 43 cases $(62.8 \%)$.

\section{Discussion}

In the present study the development and validation of a novel self-administered questionnaire for assessing the patient's own range of motion of the wrist (W-MAS) and the elbow (E-MAS) are described. This study revealed substantial to almost perfect patient-physician agreement for the self-assessment of the wrist and elbow ROM. Evaluation of patient-physician correlation demonstrated almost perfect agreement $(k>0.80)$ with regard to six of the eight items and two items (elbow extension and pronation) showed substantial agreement with $\mathrm{k}>0.70$. In the case of mismatch between patient and physician, patients tended to err towards underestimating their ROM (53 of 78 cases; $68.9 \%)$. In case of severe restriction of ROM patients tended to miss exact agreement in 23.5 to $50 \%$ in five of eight items.

The assessment of the test-retest reliability was found to be almost perfect with Cohen's kappa of $k>0.80$ for all eight items. The questionnaire revealed a high discriminative power when the healthy population was compared with the study group ( $p=0.007$ or smaller for all items).

Logistic regression analysis suggested that increasing age impairs the ability to accurately assess elbow extension $(p=0.034)$. Involvement with workers' compensation cases also appeared to influence the ability to accurately assess the pronation $(p=0.039)$.

For all other items, age and involvement in workers' compensation cases did not significantly influence the validity of the questionnaire. Gender (male vs. female) and affected side (dominant vs. non-dominant) did also not significantly influence the validity of the questionnaire. The W-MAS and the E-MAS are the first questionnaires

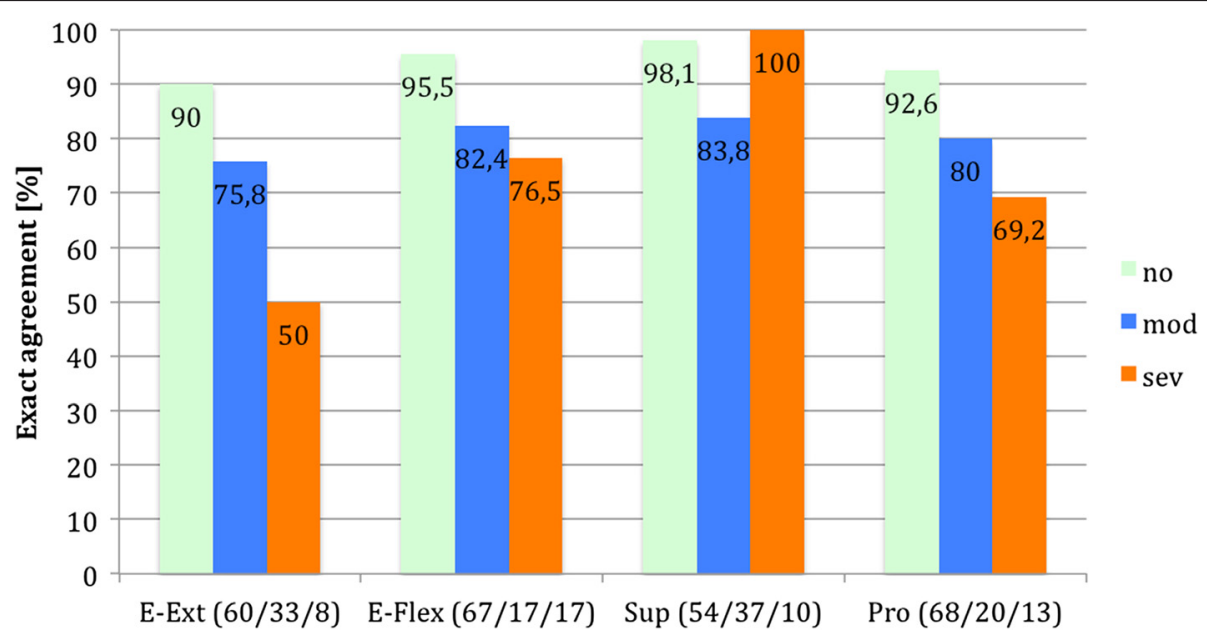

Fig. 1 Percentage of exact agreement dependent on severity of disorder (E-MAS). The number of patients for each category is shown behind its respective item 


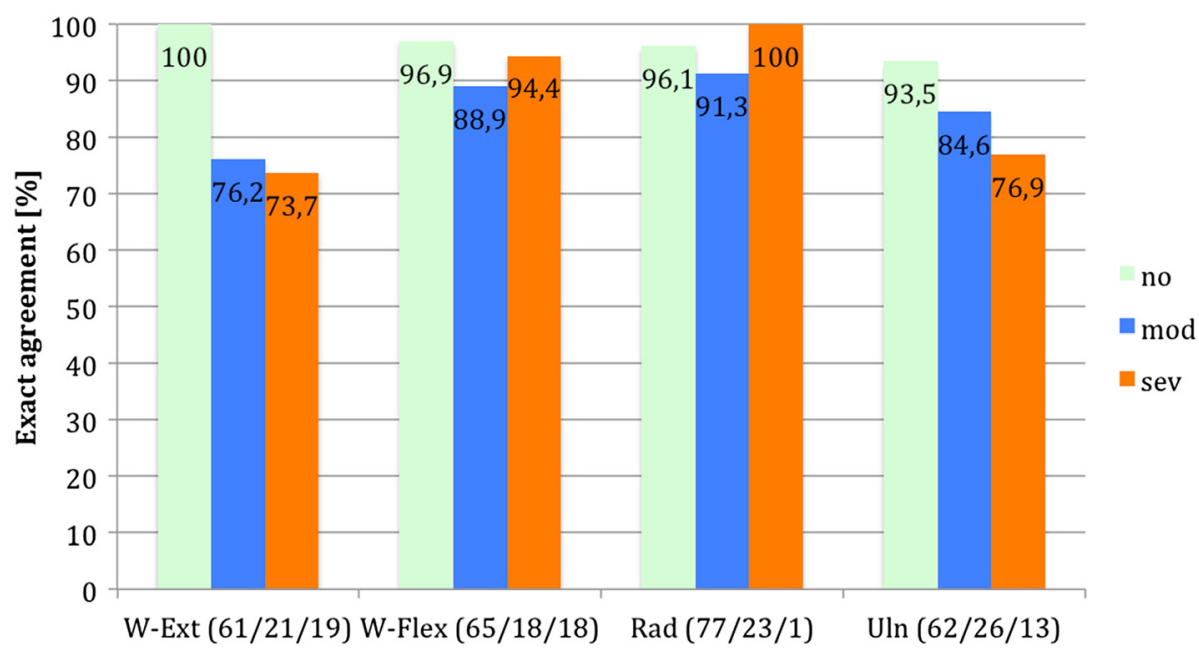

Fig. 2 Percentage of exact agreement dependent on severity of disorder (W-MAS). The number of patients for each category is shown behind its respective item

to validate the patient-physician agreement for ROM of the wrist and the elbow. According to the proposed quality criteria for measurement properties of health status questionnaires of Terwee et al. both questionnaires, the WMAS and E-MAS are fully validated [12].

Smith et al. and Carter et al. examined the agreement between physician and patient-derived values for the shoulder ROM. They concluded, that patients are able to accurately assess their own active shoulder ROM with the help of a diagram-based questionnaire, which is comparable to the results of the current study $[10,18]$.

Given the number of available wrist and elbow questionnaires, is there a need for a novel self-administered score of the elbow and the wrist? In current medical care, self-administered questionnaires are useful for the assessment of patient care and for recording outcomes in research [2, 19]. Physicians can benefit from mail-in questionnaires or internet-based reporting sites and they can use such a tool to track a patient's objective progress over time. In the same way, once a patient has been formally discharged from regular care, patient-administered questionnaires can be completed and returned via the postal service, e-mail, self-reporting website or even a smartphone app. This approach can facilitate long-term follow-up of postoperative patients for clinical trials by use of the objective criterion, ROM. According to our literature search, most available self-administered questionnaires for the wrist and the elbow do not assess ROM. Three questionnaires were identified with selfassessment of ROM, but these were not validated for patient-physician agreement. Therefore, important data regarding the ROM would be lost in patients who are unable or unwilling to come to the outpatient clinic at the regular follow-up.

Another possible advantage of self-administered questionnaires for determining $\mathrm{ROM}$ is the fact that the

Table 7 Comparison of study population with healthy population for discriminative power for the different parts of the questionnaire

\begin{tabular}{llll}
\hline Elbow; median (IQR) [in degree] & Elbow disorder $(n=79)$ & Healthy population $(n=30)$ & $p$-value* \\
extension & & & $0(0)$ \\
flexion & $10(0-20)$ & $140(0)$ & $<0.001$ \\
supination & $130(110-140)$ & $90(0)$ & $<0.001$ \\
pronation & $90(70-90)$ & Healthy population $(n=30)$ & $<0.001$ \\
& $70(50-70)$ & & 0.001 \\
Wrist; median (IQR) [in degree] & Wrist disorder $(n=22)$ & $70(70)$ & $<0(80)$ \\
extension & & $20(20)$ & $<0.001$ \\
flexion & $40(40-70)$ & $30(30)$ & $<0.001$ \\
radial deviation & $40(40-80)$ & & $<0.007$ \\
ulnar deviation & $20(17.5-20)$ & & \\
\hline
\end{tabular}


physician's influence on the data obtained is minimized. Concerns and priorities of the surgeon may differ from those of the patient [20]. On the other hand, selfassessment of objective and subjective criteria may contain some bias [21]. In this study, basic demographic data like age, gender or involvement in workers' compensation showed (except for 2 items) no significant influence on the validity and reliability of the questionnaire.

Self-administered questionnaires have some limitations. Patient-physician agreement in the assessments of the range of motion depends on the ability of the patient to understand the images given. The motion patterns given in this study are simple compared to other joints like the shoulder. All participants in the study and control group were asked about the feasibility of the questionnaire. None of the patients had any problems following the instructions and completing the questionnaire. In the current study, patients with communication problems or dyslexia were excluded, as they would not be able to provide useful information for the study.

There are certain weaknesses inherent to this study. The assessment of ROM by physician is usually represented by a continuous variable. In the current study, the assessments by physicians and the patients are both represented by ordinal variables due to practicability and comparability. As with any patient-reported outcomes survey, some patients are not able to complete the questionnaire. An inability to complete the questionnaire should alert clinicians that these patients might need to be carefully monitored between office visits or after formally discharge from care. In case of major restriction of ROM a higher percentage of disagreement between the physician and patient was found. Those patients also may require more specialized follow-up in certain settings.

This study is limited by the heterogeneity of the included injury patterns, as the majority of patients had restriction of ROM due to traumatic elbow disorders. Further study may be needed to have this questionnaire generalizable to other elbow and wrist complaints.

\section{Conclusions}

This novel, patient-administered questionnaire provides a high level of patient-physician agreement for assessing the range of motion of the wrist (W-MAS) and the elbow (E-MAS). Based on the present data, both questionnaires are quick, simple to answer, and fully validated, and can be a helpful addition to subjective self-assessment questionnaires of the wrist and the elbow. In addition with other self-assessment scores of the upper limb, these questionnaires can provide helpful information regarding $\mathrm{ROM}$ of wrist and elbow to obtain higher follow-up rates.

\section{Additional files}

Additional file 1: Elbow Motion Assessment Score (E-MAS). (PDF $306 \mathrm{~kb})$

Additional file 2: Wrist Motion Assessment Score (W-MAS). (PDF 560 kb) Additional file 3: Comparison of the range of motion of the proportion of elderly ( $\geq 54.2$ years, median) and younger patients. (DOC $31 \mathrm{~kb}$ )

\section{Abbreviations \\ ASES-E, The American Shoulder and Elbow Surgeons-Elbow; DRUJ, distal radioulnar joint; E-Ext, elbow extension; E-Flex, elbow flexion; E-MAS, elbow- motion assessment score; Pro, pronation; PRUJ, proximal radioulnar joint; PRWE, patient-rated wrist evaluation; Rad, radial deviation; ROM, range of motion; Sup, supination; Uln, ulnar deviationW-Ext, wrist extension; W-Flex, wrist flexion; W-MAS, wrist-motion assessment score}

\section{Acknowledgements}

We acknowledge the financial support by Deutsche Forschungsgemeinschaft and Ruprecht-Karls-Universität Heidelberg within the funding programme "Open Access Publishing".

\section{Funding}

This study is supported by Deutsche Forschungsgemeinschaft and Ruprecht-KarlsUniversität Heidelberg within the funding programme "Open Access Publishing".

Availability of data and materials

Data are available on request from the corresponding author.

\section{Authors' contributions}

MS and TG were involved with the design of the study, statistical analysis and manuscript preparation. SS was involved with the data interpretation, statistical analysis and manuscript preparation. HK, SA, SSF and PAG assisted with the data interpretation and manuscript preparation. All authors read and approved the final manuscript.

\section{Authors' information}

TG is senior consultants at the BG Trauma Center Ludwigshafen. PAG is the Medical Director of the BG Trauma Center Ludwigshafen.

\section{Competing interests}

The authors declare that they have no competing interests.

\section{Consent for publication}

The person that is imaged on the questionnaires gave written informed consent for publication.

\section{Ethics approval and consent to participate}

The study was approved by the local ethics committee of the board of Medical Profession of Rhineland-Palatinate in Mainz (No. 837.268.15/10036). Written informed consent was obtained from all patients participating in the study.

\section{Author details}

${ }^{1}$ Department for Trauma and Orthopaedic Surgery, BG Trauma Center Ludwigshafen at Heidelberg University Hospital, Ludwigshafen am Rhein, Germany. ${ }^{2}$ Institute of Medical Biometry and Informatics, University of Heidelberg, Heidelberg, Germany. ${ }^{3}$ Department for Trauma and Orthopaedic Surgery, BG Trauma Center Ludwigshafen at the University of Heidelberg, Ludwig Guttmann Strasse 13, 67071 Ludwigshafen am Rhein, Germany.

Received: 7 April 2016 Accepted: 8 July 2016

Published online: 26 July 2016

\section{References}

1. King GJ, Richards RR, Zuckerman JD, Blasier R, Dillman C, Friedman RJ, Gartsman GM, lannotti JP, Murnahan JP, Mow VC, et al. A standardized method for assessment of elbow function. Research Committee, American shoulder and elbow surgeons. J Shoulder Elbow Surg. 1999;8(4):351-4.

2. Longo UG, Franceschi F, Loppini M, Maffulli N, Denaro V. Rating systems for evaluation of the elbow. Br Med Bull. 2008;87:131-61. 
3. The $B$, Reininga $I H$, El Moumni M, Eygendaal D. Elbow-specific clinical rating systems: extent of established validity, reliability, and responsiveness. J Shoulder Elbow Surg. 2013;22(10):1380-94.

4. Alexander M, Franko OI, Makhni EC, Zurakowski D, Day CS. Validation of a modern activity hand survey with respect to reliability, construct and criterion validity. J Hand Surg Eur Vol. 2008;33(5):653-60.

5. Beaton DE, Katz JN, Fossel AH, Wright JG, Tarasuk V, Bombardier C. Measuring the whole or the parts? Validity, reliability, and responsiveness of the disabilities of the arm, shoulder and hand outcome measure in different regions of the upper extremity. J Hand Ther. 2001;14(2):128-46.

6. Beirer M, Friese $H$, Lenich A, Cronlein M, Sandmann GH, Biberthaler $P$, Kirchhoff $C$, Siebenlist S: The Elbow Self-Assessment Score (ESAS): development and validation of a new patient-reported outcome measurement tool for elbow disorders. Knee Surg Sports Traumatol Arthrosc. 2015 [Epub ahead of print].

7. John M, Angst F, Awiszus F, King GJ, MacDermid JC, Simmen BR. The American shoulder and elbow surgeons elbow questionnaire: cross-cultural adaptation into German and evaluation of its psychometric properties. J Hand Ther. 2010;23(3):301-13. quiz 314.

8. MacDermid JC. Development of a scale for patient rating of wrist pain and disability. J Hand Ther. 1996;9(2):178-83.

9. Naidu SH, Panchik D, Chinchilli VM. Development and validation of the hand assessment tool. J Hand Ther. 2009;22(3):250-6. quiz 257.

10. Carter CW, Levine WN, Kleweno CP, Bigliani LU, Ahmad CS. Assessment of shoulder range of motion: introduction of a novel patient self-assessment tool. Arthroscopy. 2008;24(6):712-7.

11. Moosbrugger H, Kelava A. Testtheorie und Fragebogenkonstruktion, vol. 2nd ed. Heidelberg: Springer; 2007.

12. Terwee $\mathrm{CB}$, Bot SD, de Boer MR, van der Windt DA, Knol DL, Dekker J, Bouter $L M$, de Vet HC. Quality criteria were proposed for measurement properties of health status questionnaires. J Clin Epidemiol. 2007;60(1):34-42.

13. Cutti AG, Giovanardi A, Rocchi L, Davalli A, Sacchetti R. Ambulatory measurement of shoulder and elbow kinematics through inertial and magnetic sensors. Med Biol Eng Comput. 2008;46(2):169-78.

14. Mourcou Q, Fleury A, Franco C, Klopcic F, Vuillerme N. Performance evaluation of smartphone inertial sensors measurement for range of motion. Sensors (Basel). 2015:15(9):23168-87.

15. Castaing J. Recent fractures of the lower extremity of the radius in adults. Rev Chir Orthop Reparatrice Appar Mot. 1964;50:581-696.

16. Sathyamoorthy P, Kemp GJ, Rawal A, Rayner V, Frostick SP. Development and validation of an elbow score. Rheumatology (Oxford). 2004;43(11):1434-40.

17. Landis JR, Koch GG. The measurement of observer agreement for categorical data. Biometrics. 1977;33(1):159-74.

18. Smith AM, Barnes SA, Sperling JW, Farrell CM, Cummings JD, Cofield RH Patient and physician-assessed shoulder function after arthroplasty. J Bone Joint Surg Am. 2006;88(3):508-13.

19. Simpao AF, Ahumada LM, Galvez JA, Rehman MA. A review of analytics and clinical informatics in health care. J Med Syst. 2014;38(4):45.

20. Amadio PC. Outcomes measurements. J Bone Joint Surg Am. 1993;75(11): 1583-4.

21. L'Insalata JC, Warren RF, Cohen SB, Altchek DW, Peterson MG. A selfadministered questionnaire for assessment of symptoms and function of the shoulder. J Bone Joint Surg Am. 1997;79(5):738-48.

22. MacDermid JC. Outcome evaluation in patients with elbow pathology: issues in instrument development and evaluation. J Hand Ther. 2001;14(2): 105-14.

23. Broberg MA, Morrey BF. Results of delayed excision of the radial head after fracture. J Bone Joint Surg Am. 1986;68(5):669-74.

24. Dawson J, Doll H, Boller I, Fitzpatrick R, Little C, Rees J, Jenkinson C, Carr AJ. The development and validation of a patient-reported questionnaire to assess outcomes of elbow surgery. J Bone Joint Surg Br. 2008;90(4):466-73.

25. Vincent J, MacDermid JC. Patient-rated tennis elbow evaluation questionnaire. J Physiother. 2014;60(4):240.

26. Ewald FC. Total elbow replacement. Orthop Clin North Am. 1975;6(3):685-96.

27. Khalfayan EE, Culp RW, Alexander AH. Mason type II radial head fractures: operative versus nonoperative treatment. J Orthop Trauma. 1992;6(3):283-9.

28. MacDermid JC, Tottenham V. Responsiveness of the disability of the arm, shoulder, and hand (DASH) and patient-rated wrist/hand evaluation (PRWHE) in evaluating change after hand therapy. J Hand Ther. 2004;17(1):18-23.

29. Chung KC, Pillsbury MS, Walters MR, Hayward RA. Reliability and validity testing of the Michigan hand outcomes questionnaire. J Hand Surg. 1998; 23(4):575-87.
30. Engelberg R, Martin DP, Agel J, Obremsky W, Coronado G, Swiontkowski MF. Musculoskeletal function assessment instrument: criterion and construct validity. J Orthop Res. 1996;14(2):182-92.

31. Levine DW, Simmons BP, Koris MJ, Daltroy LH, Hohl GG, Fossel AH, Katz JN. A self-administered questionnaire for the assessment of severity of symptoms and functional status in carpal tunnel syndrome. J Bone Joint Surg Am. 1993;75(11):1585-92.

32. Cooney WP, Linscheid RL, Dobyns JH. Triangular fibrocartilage tears. J Hand Surg. 1994;19(1):143-54.

33. Cooney WP, Bussey R, Dobyns JH, Linscheid RL. Difficult wrist fractures. Perilunate fracture-dislocations of the wrist. Clin Orthop Relat Res. 1987; 214:136-47

34. Bialocerkowski AE, Grimmer KA, Bain Gl. Development of a patient-focused wrist outcome instrument. Hand Clin. 2003;19(3):437-48. ix.

35. Beirer M, Serly J, Vester H, Pforringer D, Cronlein M, Deiler S, Biberthaler $P$, Kirchhoff C. The Munich Wrist Questionnaire (MWQ) - development and validation of a new patient-reported outcome measurement tool for wrist disorders. BMC Musculoskelet Disord. 2016;17(1):167

36. Lockard M. Clinical biomechanics of the elbow. J Hand Ther. 2006;19(2):72-80.

37. Ryu JY, Cooney 3rd WP, Askew LJ, An KN, Chao EY. Functional ranges of motion of the wrist joint. J Hand Surg. 1991;16(3):409-19.

\section{Submit your next manuscript to BioMed Central and we will help you at every step:}

- We accept pre-submission inquiries

- Our selector tool helps you to find the most relevant journal

- We provide round the clock customer support

- Convenient online submission

- Thorough peer review

- Inclusion in PubMed and all major indexing services

- Maximum visibility for your research

Submit your manuscript at www.biomedcentral.com/submit
) Biomed Central 